\title{
LA MUJER COMO SUJETO PARTÍCIPE DE REPARACIÓN EN EL CONTEXTO DEL POSCONFLICTO EN COLOMBIA
}

\author{
Sergio Hernando Castillo Galvis ${ }^{1}$ \\ Michelle Picón Carvajal ${ }^{2}$
}

Resumen: El presente es un artículo de reflexión que tiene por objeto de estudio analizar el rol de la mujer como sujeto partícipe de reparación en el contexto de posconflicto en Colombia. Dicho análisis parte de antecedentes normativos de carácter legal con los que históricamente se pretendió por el Estado Colombiano poner fin al conflicto armado. Para ello se abordó un marco metodológico de interés práctico, bajo paradigma hermenéutico y con enfoque cualitativo, utilizando el análisis de contenido sobre los documentos de orden normativo, jurisprudencial o doctrinal permitió el siguiente desarrollo temático: i) Analizar la situación de la mujer en el conflicto armado en Colombia; ii) La incidencia de la Ley 1448 del 2011 estudiado desde el denominado "enfoque diferencial" $\mathrm{e}$ igualmente destacando la novedad en materia de reparación, establecida en el Acuerdo Final para la Paz en Colombia que reafirma categóricamente la necesidad de un enfoque de género, concluyendo que a la fecha - de acuerdo a informes emitidos por órganos de carácter internacional - han resultado insuficientes las políticas adoptadas para garantizar la reparación integral de la mujer desde la perspectiva de análisis de género; proponiendo algunas alternativas para que le sea otorgado un rol participativo dentro de su propia reparación, entendiendo la necesidad de mecanismos o acciones que conlleven a una real y efectiva reparación integral.

Palabras Claves: Enfoque de género. Posconflicto. Reparación Integral. Mujeres Víctimas.

Abstract: This paper is a reflection which aims to analyze women's role as subjects

\footnotetext{
1 Abogado. Candidato a Magister de la Universidad Simón Bolívar Sede Cúcuta. Grupo de investigación: Tendencias jurídicas contemporáneas. Ponente en eventos nacionales e internacionales en materia de Derecho. Contacto: sergiohacstillogalvis@gmail.com

${ }^{2}$ Michelle Picón Carvajal, Abogada en formación $8^{\circ}$ semestre, adscrita al Semillero de Investigación Holístico del programa de Derecho de la Universidad Simón Bolívar Sede Cúcuta. Contacto: mpiconcarvajal@gmail.com
} 
of reparation in Colombia's post-conflict context. The analysis is performed by means of legal normative regulations which were historically intended to bring the armed conflict to an end by the Colombian state. A methodological framework of practical interest was adopted, under a hermeneutic paradigm with a qualitative approach. We used content analysis on regulations, jurisprudential and doctrinal documents enabling the following thematic issues: i) to analyze women's situation in Colombia's armed conflict; ii) the impact of the 1448 Law of the year 2011 from the "differential approach" perspective. We highlight that the Final Peace Agreement emphatically reaffirms the need for a gender approach in terms of reparation. We conclude that policies adopted thus far to ensure an integral reparation of women (from the gender analysis perspective) have proven insufficient, according to reports issued by international bodies. Finally, we propose some alternatives so that a participatory role may be granted within women's own reparation, understanding the need of schemes or actions towards a real and effective integral reparation.
Keywords: Gender approach. Post conflict. Integral reparation. Women victims

\section{INTRODUCCIÓN}

El presente es un artículo de reflexión derivado del proyecto de investigación titulado "Mecanismos para garantizar el carácter integral en la reparación a víctimas del conflicto armado interno en Colombia" que tiene por objetivo proponer un recurso que permita a la población víctima del conflicto armado, acceder de forma directa a la administración de justicia para materializar su reparación integral. Siendo conscientes del papel de la mujer dentro de la sociedad y que en múltiples casos y contextos ha sido sujeto de violaciones graves a los derechos humanos, se propone analizar la mujer como sujeto partícipe de reparación en el contexto del posconflicto en Colombia.

Para el alcance se establece un desarrollo temático así: Un primer momento se reseñará la situación de la mujer en el contexto armado a partir de revisión documental sobre Informes de la 
Comisión Interamericana de Derechos Humanos (En adelante CIDH) y el Alto Comisionado de las Naciones Unidas para los Derechos Humanos sobre la situación de los derechos humanos en Colombia, quienes denotan la grave situación de la mujer por el contexto de conflicto armado en este país; posteriormente se mencionará el avance presentado con la Ley de víctimas y su decreto reglamentario; en un tercer momento se expondrá la reparación a la mujer desde la perspectiva del Acuerdo Final para la Paz suscrito por el Gobierno Colombiano y las Fuerzas Armadas Revolucionarias de Colombia (En adelante FARC).

Desde el punto de vista metodológico se utilizó la técnica de análisis de contenido sobre documentos de carácter normativo, jurisprudencial y doctrinal para alcanzar los resultados esperados, concluyendo que existe deficiencia de los fines del Estado frente al deber de reparar a las víctimas del conflicto armado, proponiendo tres alternativas para potencializar la participación de la mujer en su propia reparación, partiendo de la importancia que tiene el denominado enfoque de género visto desde la jurisprudencia de la Corte Interamericana de Derechos Humanos (Corte IDH) y la Corte Constitucional Colombiana.

\section{DESARROLLO}

i) La mujer en el conflicto armado colombiano.

Es un hecho notorio que en Colombia desde hace más de sesenta años se ha presentado un conflicto armado interno que ha generado millones de víctimas por diferentes hechos categorizados como victimizantes ${ }^{3}$, teniendo como destinataria en múltiples casos y contextos a "la mujer"; razón por la cual en el presente acápite y de acuerdo al objeto de estudio planteado, se pretende abordar la situación de la mujer en el conflicto armado en Colombia efectuando revisión literaria de carácter constitucional, legal, reglamentaria y jurisprudencial, a nivel nacional e internacional, que permita efectuar un

\footnotetext{
${ }^{3}$ Verbigracia la descripción que realiza en su conjunto la Ley 1448 (2011) y el Decreto 4800 (2011).
} 
esbozo que se constituya como parámetro para el estudio que desde la legalidad se realizará.

$$
\text { En el contexto del conflicto }
$$
armado colombiano la mujer ha sido destinataria de graves violaciones a derechos humanos que se encuadran desde afectaciones al derecho a la vida - base esencial $^{4}$ de los demás derechos según la Corte IDH en el Caso Villagrán y otros Vs Guatemala - hasta su libertad e integridad sexual; y otros como en el Caso González ${ }^{5}$ y otras (Campo Algodonero) Vs México, traídos a colación por el desconocimiento por parte del Estado de las disposiciones previstas en la Convención Americana sobre Derechos Humanos (En adelante $\mathrm{CADH}$ ) respecto a los principios de respeto (artículo $1^{\circ}$ ) y la adecuación del sistema interno $\left(\right.$ artículo $2^{\circ}$ ), solo por mencionar algunos aspectos que serán ahondados con posterioridad.

\footnotetext{
${ }^{4}$ Véase Corte IDH, 1999. Caso de los "Niños de la Calle" (Villagrán Morales y otros) Vs Guatemala, cuando afirmó que: "El derecho a la vida es un derecho humano fundamental, cuyo goce es un prerrequisito para el disfrute de todos los demás derechos humanos. De no ser respetado, todos los derechos carecen de sentido. En razón del carácter fundamental del derecho a la vida, no son admisibles enfoques restrictivos del mismo".

5 Para este caso la Corte IDH manifestó su preocupación respecto a que la vulneración de
}

La situación particular de la mujer en el conflicto fue abordada recientemente en el Caso Yarce y Otras Vs Colombia (Corte IDH. 2016) del 22 de noviembre, en donde la Corte IDH en su ejercicio jurisdiccional para la determinación de responsabilidad internacional del Estado, aborda la problemática de la violencia contra las mujeres (p. 28) en la Comuna 13 de Medellín (Colombia), para lo cual trae a colación el informe de la Relatoría Especial del año 2001 en el cual consideró que la violencia contra las mujeres en Colombia era "habitual", "generalizada" y "sistemática" (párr. 87), e igualmente a renglón seguido reseña que en el 2002 el Informe del Alto Comisionado de las Naciones Unidas para los Derechos Humanos sobre la situación de los derechos humanos en Colombia, "recalcó que los derechos humanos de las mujeres

derechos sobre la mujer se debe al hecho de ser mujer, como lo adujo en el párrafo 164 que reza: "es preocupante el hecho de que algunos de estos crímenes parecen presentar altos grados de violencia, incluyendo sexual, y que en general han sido influenciados, tal como lo acepta el Estado, por una cultura de discriminación contra la mujer, la cual, según diversas fuentes probatorias, ha incidido tanto en los motivos como en la modalidad de los crímenes, así como en la respuesta de las autoridades frente a éstos. 
estaban siendo particularmente afectados a

raíz del conflicto armado".

A nivel interno la $\mathrm{H}$. Corte Constitucional ha identificado distintas formas de violencia contra la mujer, las cuales generan un impacto desproporcionado que discrimina, estigmatiza y la ubica en una situación de indefensión respecto de su integridad psicosocial, física y moral, especialmente en los actos que se relacionan con violencia sexual, donde ésta junto con el cuerpo de la mujer "habrían sido usados como arma y campo de guerra, respectivamente" (Corte Constitucional, 2015); encontrándose dentro de los “diez factores de vulnerabilidad específicos a los que están expuestas las mujeres por causa de su condición femenina", clasificados por la Corte Constitucional de la siguiente manera - entre otros:

“i) El riesgo de violencia sexual, explotación sexual o abuso sexual en el marco del conflicto armado. ii) El riesgo de reclutamiento forzado de sus hijos e hijas por los actores armados al margen de la ley, o de otro tipo de amenazas contra ellos, que se hace más

\footnotetext{
6 Para efectos de este artículo se tendrá como violencia contra la mujer la descrita en el artículo $1^{\circ}$ de la Convención Belém Do Pará al señalar que
}

grave cuando la mujer es cabeza de familia.; iii) Los riesgos derivados de su pertenencia a organizaciones sociales, comunitarias o políticas de mujeres, o de sus labores de liderazgo y promoción de los derechos humanos en zonas afectadas por el conflicto armado; iv) El riesgo de ser despojadas de sus tierras y su patrimonio con mayor facilidad por los actores armados ilegales dada su posición histórica ante la propiedad, especialmente las propiedades inmuebles rurales; v) Los riesgos derivados de la condición de discriminación y vulnerabilidad acentuada de las mujeres indígenas $\mathrm{y}$ afrodescendientes." (Corte Constitucional, 2008)

Aunado a lo anterior, la Corte Constitucional ha señalado que la violencia $^{6}$ ejercida en el marco del conflicto armado "afecta de manera diferencial y agudizada a las mujeres" (Corte Constitucional, 2008), especialmente en actos relacionados con violencia sexual que resultan ser un común denominador en este contexto, siendo que adicionalmente el cuerpo colegiado -

es: "cualquier acción o conducta, basada en su género, que cause muerte, daño o sufrimiento físico, sexual o psicológico a la mujer, tanto en el ámbito público como en el privado". 
mediante Auto 009 (2015)- señaló que los principales factores de orden contextual que influyen en el riesgo de violencia sexual contra mujeres, niñas, adolescentes $\mathrm{y}$ adultas mayores en el marco del conflicto armado colombiano son:

“(i) la presencia o influencia de actores armados sobre la vida individual, familiar, organizativa y comunitaria de las mujeres; y (ii) la inexistencia o precariedad del Estado frente a la prevención de la violencia sexual contra las mujeres perpetrada por actores armados".

Es de esta forma y la necesidad de transformación en esta preocupación, que la Comisión Interamericana de Derechos Humanos (CIDH) en el año 2015 realizó un informe anual respecto a la situación en Colombia, refiriéndose a las mujeres en el marco del conflicto armado, aduciendo en el Informe de Verdad, Justicia y Reparación, su preocupación por la precariedad de la situación de los derechos humanos de las mujeres en el contexto del conflicto armado interno, especialmente de las mujeres afrocolombianas, pues esta situación exacerba y agudiza su vulnerabilidad a ser víctimas de violaciones de derechos humanos, entre las que destacan el desplazamiento forzado, la violencia, la discriminación y obstáculos en su acceso a la justicia, salud y educación (párr. 262).

ii) La Mujer En La Reparación Dentro De La Ley 1448 Del 2011 Y El Decreto 4800 Del 2011

De acuerdo al contexto histórico jurídico que se había presentado con ocasión de la Ley 975 (Congreso de la República, 2005) por medio de la cual se pretendió adoptar medidas respecto a la verdad y la justicia, propendiendo por la reincorporación de miembros de grupos armados organizados al margen de la ley, cuerpo normativo de rango legal que resultó insuficiente respecto a la reparación integral de las personas víctimas del conflicto armado y con mayor rango respecto a una perspectiva de género, como bien lo señala Jimeno (2008) al manifestar que:

"Por otra parte, la Ley de Justicia y Paz aborda un camino judicial para las reparaciones. Sin embargo, una reparación integral con perspectiva de género $y$ enfoque de derechos humanos tiene que plantearse abrir caminos para una reparación 
administrativa a las mujeres víctimas del conflicto. Muchas de las violaciones a los derechos de las mujeres no podrán abordarse desde los procesos judiciales. Tienen que abrirse mecanismos y caminos que permitan la expresión y visibilización de los daños sufridos en el conflicto por las mujeres, por el hecho de ser mujeres" (p. 138)

\section{Lo anterior reafirmaba la} necesidad de mecanismos legales y reglamentarios que tuvieran por objeto el alcance de los principios y fines constitucionales en materia de reparación integral, razón por la cual, luego de múltiples pronunciamientos ${ }^{7}$ de la Corte Constitucional en que señaló la necesidad de brindar especial protección a la mujer desde una perspectiva de género ocasionando que como respuesta se sancionará y promulgará la Ley 1448 (Congreso de la República. 2011),

\footnotetext{
${ }^{7}$ Verbigracia el Auto 092 (2008) en el cual la Corte Constitucional advirtió la necesidad de una "respuesta estatal a los riesgos específicos de género en el marco del conflicto armado y a las cargas extraordinarias que deben afrontar las mujeres como consecuencia del conflicto armado", razón por la cual determinó en su numeral cuarto de la parte resolutiva que: "Para asegurar la respuesta diferencial del Estado colombiano al impacto desproporcionado del desplazamiento
}

aduciendo desde su exposición de motivos el carácter principialístico de un enfoque diferencial como respuesta estatal al manifestar - trayendo a colación disposiciones jurisprudenciales de la Corte Constitucional- que:

"Para citar un ejemplo, las mujeres, como lo ha reconocido la Corte Constitucional en el auto 092 de 2008, enfrentan patrones sociales de discriminación, exclusión y violencia que son potenciados este punto, es importante tener presente que si bien tanto los hombres como las mujeres son víctimas de violaciones a los Derechos Humanos e infracciones al Derecho Internacional Humanitario, "en el caso de las mujeres, a los actos de violencia física y psicológica, se suman agresiones y delitos de índole sexual". Este tipo de violencia no recibe la misma atención que otras violaciones de Derechos Humanos, ya que

\begin{tabular}{l} 
es vista como una \\
circunstancia cotidiana 0 \\
\hline menos importante. Sin \\
\hline
\end{tabular}

forzado sobre las mujeres, se ORDENA al Director de Acción Social que adopte las medidas necesarias para garantizar que las dos presunciones constitucionales que amparan a las mujeres desplazadas en tanto sujetos de protección constitucional reforzada, descritas en las secciones V.A.8. y V.C. de la presente providencia, sean incorporadas al SNAIPD y conocidas, comprendidas y aplicadas adecuadamente por todos los funcionarios encargados de velar por los derechos de las mujeres desplazadas. 
embargo, debe tenerse en cuenta que la violencia contra las mujeres ha sido empleada como una estrategia de guerra, no solo para la afectación directa de las víctimas sino para impartir terror en la comunidad y lograr el control de territorios y recursos. Además, tal y como lo ha señalado la Comisión Interamericana de Derechos Humanos, las mujeres resultan afectadas como víctimas directas así como por sus vínculos afectivos como hijas, madres, esposas, compañeras, o hermanas".

Por lo anterior, con el fin de garantizar y materializar los derechos constitucionales de las personas víctimas del conflicto armado interno en Colombia, se crea la ley de víctimas y restitución de tierras (Ley 1448 del 2011) que junto con su decreto reglamentario 4800 del 2011, constituyen un marco normativo garantista e incluyente para la defensa y respuesta a las necesidades de las víctimas, con el ámbito de aplicación concerniente a "ayuda humanitaria, atención, asistencia y reparación de las víctimas, [...] ofreciendo herramientas para que estas reivindiquen

\footnotetext{
${ }^{8}$ La cual, de acuerdo a su artículo $1^{\circ}$, tiene como
} principal objeto "establecer un conjunto de su dignidad y asuman su plena ciudadanía"

(Congreso de la República, 2011).

\section{La Corte Constitucional}

(Sentencia T - 418, 2015), ha expresado que existe "un número significativo de riesgos de género en el marco del conflicto armado colombiano, que son a su vez factores específicos de vulnerabilidad a los que están expuestas las mujeres por causa de su condición femenina", para la reparación de las mujeres que por el contexto del conflicto armado adquieren la categoría de víctimas dentro del marco de la ley 1448 de $2011^{8}$, que en su artículo $8^{\circ}$ establece como principio el enfoque diferencial, manifestando el reconocimiento a poblaciones con características particulares asignando a la mujer la categoría de "especial protección" con respecto a las garantías y medidas de protección.

En cumplimiento de las normas de carácter constitucional, se expidió el decreto 4800 del 2011 (reglamentario de la ley 1448 del 2011), en virtud del cual surge la obligación de crear directrices especializadas para materializar el enfoque

medidas judiciales, administrativas, sociales y económicas, individuales y colectivas, en beneficio de las víctimas" (Congreso de la República, 2011). 
psicosocial en las medidas de reparación, y así mismo, en "todas las acciones, planes y programas de atención, asistencia y reparación integral que se implementen en el marco de la Ley 1448 de 2011" (Congreso de la República, 2011). Adicionalmente se propende la participación activa de las víctimas a través de organizaciones por éstas conformadas, tal como lo prevé el numeral $10^{\circ}$ del artículo 286 del Decreto 4800 (Presidencia de la República. 2011) al manifestar que el protocolo de participación activa debe incluir mecanismos de fortalecimiento a estas entidades (organizaciones, corporaciones o en general persona jurídicas) conformadas por grupos rurales, juveniles y mujeres.

En la próximas líneas se abordará el papel de la mujer en la reparación desde el Acuerdo Final para la Paz suscrito a finales del 2016 en Colombia, buscando establecer las condiciones para alcanzar el fin del conflicto y consecuentemente "una paz estable y duradera", partiendo del informe emitido por la CIDH (2015, p. 830) que reafirma la necesidad de implementar esfuerzos concretos para cumplir con sus cuatro obligaciones: la prevención, la investigación, la sanción y la reparación de violaciones de los derechos humanos de las mujeres.

iii) La Mujer En La Reparación Dentro Del Acuerdo Final Para La Paz.

Como resultado de una serie de negociaciones y acuerdos entre el Gobierno Nacional y el grupo insurgente denominado como "Fuerzas Armadas Revolucionarias de Colombia" (FARC), se lleva a cabo el Acuerdo Final para la Paz, el cual, tiene como finalidad "contribuir a las transformaciones necesarias para sentar las bases de una paz estable y duradera"(p.7); aquel, en materia de reparación, trae consigo un sistema integral que cuenta con un enfoque diferencial y de género que "se ajusta y responde a las características particulares de la victimización en cada territorio y cada población, y en especial a las necesidades de las mujeres y de los niños y las niñas" (p.128), a través de la participación de representantes y organizaciones de mujeres, las cuales cuentan con necesidades particulares que se tendrán en cuenta con el fin de materializar lo anterior bajo la 
implementación de principios como el enfoque de género que consiste en:

"El reconocimiento de la igualdad de derechos entre hombres y mujeres y de las circunstancias especiales de cada uno, especialmente de las mujeres independientemente de su estado civil, ciclo vital y relación familiar y comunitaria, como sujeto de derechos y de especial protección constitucional. [...] " (Acuerdo Final para la Paz, p.193)

Así mismo, se estipuló dentro del Acuerdo como uno de los principales objetivos del Sistema Integral, el "enfoque territorial, diferencial y de género" (p.128), otorgando prioridad al tratamiento especial que debe recibir la mujer, lo que representa (por lo menos en teoría) un avance importante, teniendo en cuenta que concede un espacio de atención y asistencia particular y especializado a los grupos más vulnerables del conflicto armado.

Al reconocer la importancia de la participación que tiene la mujer a la hora de evaluar necesidades particulares con enfoque de género en el contexto del conflicto armado, en Colombia se han ejecutado labores por medio de políticas para la promoción y protección de los derechos de las mujeres, atendiendo a las recomendaciones formuladas por la $\mathrm{CIDH}$ en lo que tiene que ver con la implementación de medidas eficaces para prevenir, sancionar y erradicar la violencia y discriminación contra las mujeres en el marco del conflicto armado, según el informe anual del 2015 emitido por la $\mathrm{CIDH}$, fomentando la creación de grupos o equipos denominados "duplas de género" que tienen como función principal:

“(i) ejecutar acciones a nivel regional para la prevención de la violencia de género, incluyendo acciones de capacitación y formación, y acompañamiento a organizaciones, grupos $\mathrm{o}$ colectivo; (ii) brindar atención, asesoría, orientación y acompañamiento psicosocial o jurídico a mujeres, víctimas de discriminación o violencia en razón de género; (iii) realizar diagnósticos regionales sobre la situación de los derechos humanos de las mujeres; y (iv) participar en espacios interinstitucionales a nivel regional que permitan mejorar las rutas para la atención, protección y defensa de los derechos humanos de las mujeres" CIDH (2015, p. 834) 


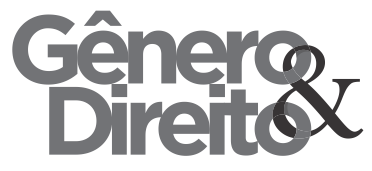

Con lo anterior se observa un avance importante hacia la materialización de los derechos y garantías derivadas del deber estatal de reparar integralmente a las víctimas del conflicto armado en plena observancia de enfoque de género, por lo cual el período de implementación de los acuerdos requiere medidas reales que permitan efectivizar sus disposiciones para que cumplan con los objetivos y fines trazados para el fin del conflicto armado y el alcance de una paz estable y duradera, propendiendo por accione s que garanticen la participación de la mujer en su reparación, desde su dimensión individual y colectiva abordando sus componentes de indemnización, satisfacción, rehabilitación y restitución.

\section{CONCLUSIÓN}

Existe una evolución normativa y jurisprudencial importante en materia de enfoque de género al interior del ordenamiento jurídico colombiano respecto a la reparación integral de la

\footnotetext{
9 A modo de contextualización puede tenerse en cuenta que los hechos de Mapuján - de forma muy suscinta- se resumen en que el 10 de marzo del 2000 miembros de grupos armados ilegales
}

mujer como sujeto de especial protección constitucional, esto como respuesta de informes y requerimientos realizados por órganos internacionales que han denotado la situación de la mujer en el conflicto armado interno, afirmando categóricamente la insuficiencia que a la fecha presentan las normas de carácter legal y reglamentario en la reparación integral efectiva.

\section{PROPUESTAS}

i) La mujer como sujeto principal y definidor de su propia reparación: Caso Tejedoras de Mapuján. El caso de las mujeres de la Comunidad de Mapuján, ${ }^{9}$ quienes mediante expresión artística de su cultura, manifiestan relatos a través de tejidos, buscando una manera particular de rehabilitación y así superar cualquier el hecho de desplazamiento forzado del que fueron víctimas, otorgando participación a la mujer en su propia reparación, como bien lo señala Parra (2014, p. 37) que aduce:

"las víctimas y las mujeres
que son objeto de graves

denominados como "paramilitares" asesinaron a once campesinos que tuvo como consecuencia el desplazamiento de 1.100 personas en la vereda de Mapuján, a dos horas de Cartagena. 
violaciones a los derechos humanos, tengan la posibilidad y las condiciones jurídicas, sociales y personales, necesarias para construir sobre las adversidades y el dolor, relatos que promuevan una paz interrelacional, duradera y estable."

En concordancia es posible la optimización de resultados a través de la formulación de proyectos de emprendimiento para mujeres víctimas del conflicto armado propendiendo por su reparación, asumiendo un rol activo en ello, por ejemplo las convocatorias realizadas por el Banco de Desarrollo Empresarial (BANCOLDEX) que actualmente tiene una que busca "asignar recursos de cofinanciación no reembolsables a propuestas cuya finalidad sea crear modelos de microfranquicias para población víctima del desplazamiento forzado en Colombia, que permitan el crecimiento de sus Mipymes y la creación de unidades de negocio formales que garanticen la generación de ingresos sostenibles"10.

\footnotetext{
${ }^{10}$ Disponible en:

https://www.innpulsacolombia.com/es/ofertas
}

\section{ii) Políticas públicas hacia la reparación} integral de las mujeres víctimas. Sin lugar a dudas el Estado, a través de políticas públicas, está en la obligación de proponer proyectos, actividades y programas enfocados al cumplimiento de los elementos y componentes de la reparación integral de las mujeres víctimas del conflicto armado, fundamentado en la importancia que tiene el "análisis de género" buscando que la mujer desarrolle un papel protagónico en su propia reparación, partiendo de la importancia de emprender medidas para la protección y efectividad especial de sus derechos por medio de instrumentos como la CEDAW, que como bien lo afirmó el juez Cancado Trindade en el Caso Miguel Castro y otros Vs Perú, su entrada en vigor "fortaleció el derecho de petición individual internacional, ampliando considerablemente, con enfoque de género, los círculos de personas protegidas, al abarcar los derechos de la mujer como jurídicamente exigibles" (p. 19), expresando, en su artículo 2 , el deber estatal de seguir una política encaminada a eliminar la discriminación contra la mujer 


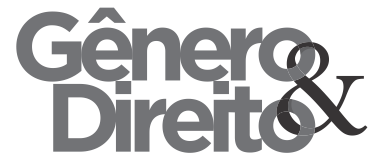

adoptando medidas adecuadas, legislativas y de otro carácter, con las sanciones correspondientes, que prohíban esta práctica.

iii) El control de convencionalidad respecto a la efectividad de los derechos y garantías de la mujer. Desde el año 2006 con el Caso Almonacid Arellano Vs Chile la Corte IDH estableció que los jueces de la república están llamados a ejercer una "especie de control de convencionalidad" entre las normas y prácticas internas respecto a la CADH y la interpretación que de esta realiza la Corte IDH. Adicionalmente a ello, en el año 2011 con el fallo del Caso Gelman Vs Uruguay, la Corte IDH amplió el espectro manifestando que todas las autoridades públicas estaban llamadas a ejercer el control de convencionalidad buscando la conformación de un ius commune internacional. Lo anterior se traduce en que todos los estamentos y funcionarios

\footnotetext{
${ }^{11}$ Véase el desarrollo jurisprudencial emprendido por la Corte IDH desde la emisión de la Sentencia en el Caso Velásquez Rodríguez Vs Honduras (1989).

${ }^{12}$ El artículo 7 en su literal g señala como deber del Estado: "g. establecer los mecanismos judiciales y administrativos necesarios para asegurar que la mujer objeto de violencia tenga acceso efectivo a
}

dico do Núcleo de Estudos e Pesquisas sobre Gênero e Direito Centro de Ciências Jurídicas - Universidade Federal da Paraíba V. 6 - No 03 - Ano 2017 (Spanish Edition) instrumento teniendo como presupuesto la CADH en sí misma y, para el caso de la protección especial a la mujer, la Convención Belém Do Pará dado el reconocimiento al carácter jurisdiccional del Tribunal Interamericano, fijando además precedente jurisprudencial con la interpretación que realiza de estos instrumentos en múltiples vertientes: a) Desde el ámbito de la reparación; ${ }^{11}$ b) Desde la protección especial con la cual debe gozar la mujer; ${ }^{12}$ c) $\operatorname{Deber}^{13}$ de investigar, juzgar y sancionar del Estado; entre otras.

\section{BIBLIOGRAFÍA}

Alto Comisionado para la Paz. (24 de Noviembre de 2016). Acuerdo Final para la Terminación del Conflicto y el Alcance a una Paz Estable y duradera. Recuperado de

http://www.altocomisionadoparalapaz.go

resarcimiento, reparación del daño u otros medios de compensación justos y eficaces". Siendo válido mencionar que de acuerdo a autores como Quinche (2014) reconoce el orden jurisdiccional de la Corte IDH conllevando la aplicación del control incluso sobre sus disposiciones.

${ }^{13}$ Originada desde las disposiciones mismas de la Convención Americana de Derechos Humanos. 


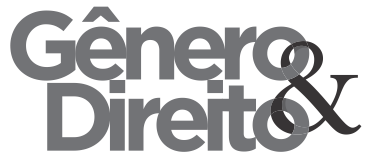

v.co/procesos-y-

conversaciones/Documentos\%20comparti

dos/24-11-2016NuevoAcuerdoFinal.pdf

Comisión Interamericana de Derechos

Humanos. (2015). Capítulo V.

Seguimiento de recomendaciones

formuladas por la CIDH en el informe

Verdad, Justicia y Reparación: Cuarto informe sobre la situación de Derechos Humanos en Colombia. Recuperado de http://www.oas.org/es/cidh/docs/anual/20

\section{5/doc-es/InformeAnual2015-cap5-}

\section{Colombia-ES.pdf}

Congreso de la República de Colombia. (10 de Junio de 2011). Por la cual se dictan medidas de atención, asistencia y reparación integral a las víctimas del conflicto armado interno y se dictan otras disposiciones. [Ley 1448]. DO: 28096

Congreso de la República de Colombia. (20 de Diciembre de 2011). Por el cual se reglamenta la Ley 1448 de 2011 y se dictan otras disposiciones. [Decreto 4800]. DO: 48280

Congreso de la República de Colombia. (25 de Julio de 2005). Por la cual se dictan ódico do Núcleo de Estudos e Pesquisas sobre Gênero e Direito Centro de Ciências Jurídicas - Universidade Federal da Paraíba V. 6 - No 03 - Ano 2017 (Spanish Edition) disposiciones para la reincorporación de miembros de grupos armados organizados al margen de la ley, que contribuyan de manera efectiva a la consecución de la paz nacional y se dictan otras disposiciones para acuerdos humanitarios. [Ley 975]. DO: 45980

Corte Constitucional de Colombia. (14 de Abril de 2008). Auto 092 [MP. Manuel José cepeda Espinosa].

Corte Constitucional de Colombia. (27 de Enero de 2015). Auto 009 [MP. Luis Ernesto Vargas Silva].

Corte Constitucional de Colombia. (3 de Julio de 2015) Sentencia T-418. [MP. Jorge Ignacio Pretelt Chaljub].

Corte Interamericana de Derechos Humanos. (16 de noviembre de 2009) Caso González y Otras ("Campo Algodonero") vs. México.

Corte Interamericana de Derechos Humanos. (19 de noviembre de 1999) Caso de los "Niños de la Calle" (Villagrán Morales y otros) Vs. Guatemala. 
Corte Interamericana de Derechos

Humanos. (22 de Noviembre de 2016)

Caso Yarce y Otras Vs Colombia.

Corte Interamericana de Derechos

Humanos. (24 de Febrero de 2011) Caso

Gelman Vs. Uruguay

Corte Interamericana de Derechos

Humanos. (25 de Noviembre del 2006).

Caso del Penal Miguel Castro Castro Vs.

Perú

Corte Interamericana de Derechos

Humanos. (26 de Septiembre de 2006)

Caso Almonacid Arellano y otros Vs.

Chile

Organización de los Estados Americanos (O.E.A). (06 de septiembre de 1994) Convencion Interamericana para Prevenir, Sancionar y Erradicar la Violencia contra la Mujer "Convencion do Belem do Pará"

Organización de los Estados Americanos (O.E.A). (22 de noviembre de 1969) Convención Americana de Derechos Humanos.
Parra Parra, L.A. (2014). Entre puntadas, palabras y duelos, las "Tejedoras de sueños" en Mapuján aportan a la construcción de paz. (Trabajo de grado, Universidad Nacional de Colombia). Recuperado de http://www.bivipas.unal.edu.co/bitstream/ 10720/686/1/1010191990-2014.pdf 